\title{
ANALISIS SISTEM REWARD DAN PUNISHMENT TERHADAP KINERJA PEGAWAI
}

Fa'iqotul Fauziyah, Rio Renaldi

IAIN Syekh Nurjati Cirebon, AMIK Bumi Nusantara Cirebon, Indonesia

Email: faiqotulfauziyah51@gmail.com,rio71933@gmail.com

Abstrak
Latar belakang: Dalam era sekarang ini banyak perusahaan yang menerapkan sistem syariah dalam operasioanalnya termasuk penerapan reward dan punishment, namun tidak semua perusahaan bisa mengaplikasikan reward dan punishment yang benar-benar telah disesuaikan. Tujuan penelitian: Tujuan penelitian ini adalah untuk mengetahui bagaimana analisis sistem reward dan punishment yang ada di Bank Muamalat Cirebon serta bagaimana sistem reward dan punishment terhadap kinerja karyawan Bank Muamalat Cirebon.

Metode penelitian: Metode penelitian yang digunakan dalam penelitian ini adalah penelitian kualitatif yang berupa studi kasus. Tempat penelitian ini adalah di Bank Muamalat Cirebon. Teknik pengumpulan data dengan metode wawancara dan dokumentasi dengan validitas data menggunakan triangulasi. Analisis data dengan menggunakan data collection, data reduction, data display, dan conlussion drawing/verification.

Hasil penelitian: Hasil dari penelitian ini ditemukan bahwa sistem reward dan punishment ini perlu diberlakukan karena semakin mempengaruhi kinerja karyawan. Karyawan semakin bertanggung jawab dalam bekerja sesuai job description, memiliki tugas atau target yang harus dicapai masing-masing, baik secara pribadi maupum team. Minimalnya, karyawan mampu mencapai setengah dari total keseluruhan target KPI. Adanya reward berupa insentif dan kenaikan jenjang karir, semakin mempengaruhi kinerja karyawan.

Kesimpulan: Kesimpulan dari penelitian ini adalah bahwa karyawan Bank Muamalat Cirebon dengan adanya sistem reward yang disiapkan oleh manajemen makin termotivasi untuk bekerja, diawali niatan Lillahi taála, mereka semakin memiliki target atau tujuan yang terarah dan jelas. Sedangkan punishment dalam praktiknya hampir tidak ditemukan di lokasi penelitian, hal ini selain manajemen sudah menerapkan regulasi punishment, juga karena karyawan Bank Muamalat Cirebon menyadari bahwa bekerja merupakan ibadah.

Kata kunci: Reward, Punishment, Kinerja, Bank Muamalat

\section{Abstract}

Background: In today's era, many companies implement the Sharia system in their operations, including the application of rewards and punishments, but not all companies can apply rewards and punishments that have truly been adjusted.

The purpose of the study: The purpose of this study was to find out how to analyze the reward and punishment system in Bank Muamalat Cirebon employees also to find out how to analyze the reward and punishment system for Bank Muamalat Cirebon employees performance.

Research method: The research method used in this research is qualitative research in the form of case studies. The place of this research is at Bank Muamalat Cirebon. Data collection techniques with interview and documentation methods with data validity using triangulation. Data analysis using data collection, data reduction, data presentation, and drawing conclusions/verification.

The results of the study: The results of this study found that the reward and punishment system needs to be implemented because it increasingly affects employee performance. Employees are increasingly responsible for working according to job descriptions, each having tasks or targets that must be achieved, both individually and as a team. At a minimum, employees are able to achieve half of the total KPI targets. The existence of rewards in the form of incentives and career advancement, increasingly affects employee performance.

Conclusion: The conclusion of this study is that employees of Bank Muamalat Cirebon with a

\begin{tabular}{ll}
\hline & Fa'iqotul Fauziyah, Rio Renaldi. (2021). Analisis Sistem Reward dan Punishment Terhadap \\
How to cite: & Kinerja Pegawai. Co-Value: Jurnal Ekonomi, Koperasi Kewirausahaan Vol 12(3): 106-113 \\
\hline E-ISSN: & https://greenpublisher.id/ \\
\hline Published by: &
\end{tabular}


reward system prepared by management are more motivated to work, starting with Lillahi taála's intentions, they increasingly have targeted and clear targets or goals. While punishment in practice is almost not found in the research location, this is in addition to the management having implemented punishment regulations, also because Bank Muamalat Cirebon employees realize that work is worship.

Keywords: Reward, Punishment, Performance, Bank Muamalat

Diterima: 26-11-2021; Direvisi: 6-12-2021; Disetujui: 6-12-2021

\section{PENDAHULUAN}

Dalam perkembangan dunia bisnis yang semakin meningkat mendorong semakin tinggi pula tingkat persaingan dalam bidang usaha, tidak terkecuali dalam sektor jasa.(Agustina et al., n.d.) Seiring dengan perkembangan tersebut, masalah yang dialami perusahaan semakin kompleks karena perusahaan akan menghadapi lebih banyak pesaing, namun perusahaan dituntut untuk dapat mencapai penjualan produk sesuai dengan target yang diharapkan melalui peningkatan kualitas pelayanan sumber daya manusia (SDM).(Hariyati, 2011)

Kualitas pelayanan sumber daya manusia yang maksimal terhadap konsumen sangat diperlukan dalam menjaga dan meningkatkan kualitas perusahaan.(Pramesti et al., 2019) Mengingat pentingnya sumberdaya manusia yang mencakup peran, pengelolaan, serta pendayagunaan karyawan diperlukan untuk memacu semangat kerja karyawan, perusahaan harus memenuhi beberapa kriteria melalui penerapan konsep dan teknik manajemen sumberdaya yang tepat salah satunya pemberian reward dan punishment.

Setiap organiasasi akan segera berkemas dan menyusun strategi baru dalam manajemennya, tak terkecuali dalam manajemen SDI.(Tangkuman et al., 2015) Beberapa poin penting yang menjadi aktivitas SDM yaitu penilaian kompetensi karyawan untuk melihat kemampuan SDM, serta pemberian reward dan punishment untuk menstimulasi dan memotivasi tenaga kerja agar lebih bersemangat dan produktif.

Allah memperingatkan manusia melalui ayat diatas bahwa setiap tindakan dan perilaku mereka akan dibalas dengan seadil-adilnya. Hal ini menunjukan bahwa reward dan punishment sudah diajarkan dalam Islam sebagai peringatan bagi manusia agar menjalani hidup sesuai dengan syariat yang ditentukan oleh Allah.(Rismanto, 2019)

Reward dan punishment adalah dua kata yang saling bertolak belakang akan tetapi, kedua hal tersebut saling berkaitan, keduanya memacu karyawan untuk meningkatkan kualitas kerja.(Rismawan \& Ar-rasyid, 2018) Reward dan punishment sangat erat hubungannya dengan pemberian motivasi karyawan tak terkecuali pada karyawan yang bergerak pada lembaga perbankkan dan non-perbankan.

Reward dan punishment sangat erat hubungannya dengan pemberiaan motivasi karyawan tak terkecuali pada karyawan yang bergerak pada lembaga perbankan dan non perbankan. Persaingan lembaga perbankan dan non perbankan semakin hari semakin ketat membuat persaingan semakin tajam sehingga setiap lembaga dituntut untuk memiliki strategi dalam meningkatkan kinerja karyawan salah satunya pada bank syariah Indonesia (Febrianti, 2014). Tidak hanya membantu untuk meningkatkan kinerja, punishment juga berguna untuk meningkatkan motivasi karyawan. Punishment diperlukan dalam meningkatkan motivasi dalam berkerja dan mendidik karyawan supaya menaati semua peraturan perusahaan (Hidayat, 2018). Dengan keadilan dan ketegasan, sasaran 
pemberian punishment akan tercapai. Peraturan tanpa diiringin pemberian punishment yang tegas bagi pelanggarnya bukan menjadi alat pendidik bagi karyawan.

Kinerja Karyawan adalah hasil pekerjaan yang dicapai seseorang berdasarkan persyaratan-persyaratan (job requirement). Suatu pekerjaan mempunyai persyaratan tertentu untuk dapat dilakukan dalam mencapai tujuan yang disebut juga sebagai standar pekerjaan. Kinerja yang baik merupakan suatu langkah untuk menuju tercapainya individu.(Kurniawan \& Alimudin, 2015) Oleh karena itu, kinerja merupakan sasaran penentu dalam mencapai tujuan individu. Dengan menerapkan reward dan punishment yang telah disesuaikan. Dalam era sekarang ini banyak perusahaan yang menerapkan sistem syariah dalam operasioanalnya termasuk penerapan reward dan punishment, namun tidak semua perusahaan bisa mengaplikasikan reward dan punishment yang benar-benar telah disesuaikan.

Seperti halnya dalam Bank Muamalat Cirebon yang juga mengusung nilai-nilai Islam dalam kinerjannya dan telah menerapkan sistem reward dan punishment dalam bank-nya. Reward yang telah diterapkan dalam Bank Muamalat Cirebon tersebut diantarannya melalui pemberian pujian bagi karyawan dari atasan, pemberian kompensasi, penambahan bonus, dan pemberian hadiah bagi karyawan berprestasi yang telah memenuhi syarat dan kriteria tertentu yang telah ditetapkan di Bank Muamalat Cirebon tersebut. Punishment yang telah diterapkan di Bank Muamalat Cirebon tersebut diantarannya melalui teguran dari atasan ke karyawan yang telah dirasa lalai dalam melakukan kewajiban bekerja, melalui surat peringatan, sanki bagi karyawan yang lalai dalam bekerja serta potongan gaji.

Hal inilah yang membuat peneliti tertarik untuk melakukan penelitian di Bank Muamalat Cirebon, karena telah menerapkan sistem reward dan punishment dalam sistem kerjannya. Oleh karena itu penelitian ini dilakukan dengan tujuan untuk mengetahui pemberian reward dan punishment yang ada di BSI tersebut apakah memberikan sumbangsih positif terhadap kinerja karyawan.

\section{METODE PENELITIAN}

Penelitian ini merupakan penelitian kualitatif deskriptif, yaitu penelitian yang membentuk, menggambarkan secara beruntut dan tersistem, faktual, dan pasti mengenai penerapan reward dan punishment pada karyawan Bank Muamalat Cirebon. Penggunaan desain penelitian deskriptif kualitatif dalam penelitian ini diharapkan untuk menggabarkan, mendeskripsikan dan menganalisis penerapan reward dan punishment pada karyawan Bank Muamalat Cirebon. Penelitian ini dilaksanakan di Bank Muamalat Cirebon KC Siliwangi Cirebon. Penelitian ini difokuskan kepada karyawan-pegawai Bank Muamalat Cirebon. Penelitian dengan metode kualitatif menggunakan teknik pengumpulan data dengan metode wawancara, observasi dan dokumentasi dengan validitas data menggunakan triangulasi.

\section{HASIL DAN PEMBAHASAN}

\section{1). Analisis Sistem Reward dan Punishment yang Ada di Bank Muamalat Cirebon}

Di Bank Muamalat Indonesia Cabang Cirebon, Karyawan mendapatkan upah atas pekerjaannya berupa gaji pokok dan beberapa insentip atau bonus (reward). Untuk gaji pokok sendiri setiap karyawan mendapat gaji yang berbeda-beda tergantung dari jabatannya. Adapun sistem penggajian terdiri dari 3 prosedur, yaitu: prosedur pencatatan waktu hadir, prosedur pembuatan daftar gaji, prosedur pembayaran gaji. 


\section{Prosedur Pencatatan Waktu Hadir}

Prosedur ini bertujuan untuk mencatat waktu hadir karyawan. Prosedur ini dikelola oleh unit opersional cabang dengan menggunakan sistem MHP (Muamalat Human Power). Sistem MHP ini secara online dan otomatis terkoneksi dengan sistem penggajian. Sekaligus system tersebut melakukan pemotongan penghasilan pegawai berdasarkan hari tidak masuk kerja.

2.Prosedur Pembuatan Daftar Gaji

PT, Bank Muamalat Indonesia Cabang Ciledug menggunakan daftar induk penggajian secara sistematis dengan program yang terkomputerisasi dengan sistem MHP (Muamalat Human Power). Dalam prosedur ini fungsi pembuatan daftar gaji karyawan dikelola oleh unit operasional kantor cabang.

Menurut hasil wawancara penelitian kepada Bapak Muhamad Zakaria selaku Coordinator Of Financing Bank Muamalat Cirebon tersebut menyimpulkan bahwa system reward dan punishment memang ada dan berlaku di lingkungan kerja karyawan Bank Muamalat Cirebon. Adapun untuk penilaian reward dan punishment karyawan dilihat dari sejauh mana karyawan mampu memenuhi dan mencapai KPI atau Key Performance Indicator mereka.(Yolanda et al., 2018) Lebih lanjut, Bapak Mohamad Zakaria juga menjelaskan dalam wawancara yang dilakukan pada hari Rabu, 1 Desember 2021 pukul 09:00 WIB sampai dengan selesai di Bank Muamalat Cirebon yang beralamatkan di Jl. Siliwangi No. 60 Cirebon, Jawa Barat tentang bentuk-bentuk reward.

Berdasarkan hasil wawancara di atas dapat ditemukan satu jenis reward yang berlaku di Bank Muamalat Cirebon adalah dengan pemberian uang insentif di luar gaji pokok sebesar 0,01 dari target yang didapat yang akan dibayarkan di bulan berikutnya. Jika nominal yang ditargetkan ialah sebesar 10.000.000 rupiah maka Karyawan akan mendapatkan reward sebesar 100.000 rupiah dan seterusnya.(Sumaeni, 2018) Selanjutnya, bentuk reward lain selain pemberian uang insentif adalah dengan menaikan jabatan sesuai dengan jenjang karir yang berlaku di Bank Muamalat Cirebon. Hal ini sesuai dengan jawaban wawancara yang dilakukan pada hari Rabu, 1 Desember 2021 pukul 09:00 WIB sampai dengan selesai di Bank Muamalat Cirebon yang beralamatkan di Jl. Siliwangi No. 60 Cirebon.

Ditinjau dalam perspektif ekonomi syariah, dalam menghadapi perubahan dan kemajuan sains teknologi yang pesat haruslah didasarkan kepada maslahah.(Ishak, 2014) Para ulama menyatakan "di mana ada maslahah, maka di situ ada syariah Allah". Ini berarti bahwa segala sesuatu yang mengandung kemaslahatan, maka di sana ada syariah Allah. Dengan demikian mashlahah adalah konsep paling utama dalam syariat Islam. Oleh sebab itu system reward dan punishment merupakan suatu metode yang dapat meningkatkan etos kerja karyawaan, jika melihat dari segi mashlahah memiliki nilai legalitas formal. Artinya sah-sah saja diterapkan dalam dunia bisnis asal tidak bertentangan dengan nilai-nilai syari'ah.(Assagaf, n.d.)

Menurut hasil wawancara penelitian tersebut dapat disimpulkan bahwa system punishment juga ada dan berlaku di Bank Muamalat Cirebon. Punishment diberikan kepada karyawan yang tidak mampu mencapai setengah atau 50\% target KPI. Adapun KPI untuk setiap Karyawan berbeda-beda sesuai dengan jabatan dan jobdesc-nya masingmasing. Untuk karyawan yang bekerja di bagian marketing maka target KPI adalah nasabah baru, sedangkan untuk bagian finance maka targetnya adalah jumlah nominal transaksi.(DANANTO, 2018) Selain itu, didalam KPI juga terdapat penilaian mengenai kedisiplinan waktu dalam bekerja. Apabila karyawan terlambat maka ia target KPI akan berkurang nilainya. Selain itu masih ada banyak indikator lainnya yang terdapat dalam KPI yang menjadi penilaian kinerja karyawan. Para karyawan harus dapat memenuhi indikator tersebut sehingga akumulasi nilai kinerjanya bisa melebihi $70 \%$ nilai maksimal. 
Adapun jika nilai KPI dari berbagai indikator tersebut kurang dari 50\% maka karyawan tersebut akan mendapatkan punishment. Namun, pemberian punishment dilakukan secara bertahap mulai dari pemberian surat teguran atau ST, surat peringatan atau SP bahkan hingga akan di-PHK.

Hal ini sesuai dengan jawaban wawancara yang dilakukan pada hari Rabu, 1 Desember 2021 pukul 09:00 WIB sampai dengan selesai di Bank Muamalat Cirebon yang beralamatkan di Jl. Siliwangi No. 60 Cirebon.

Dari segi ekonomi syariah, system reward dan punishment merupakan salah satu alat untuk peningkatan motivasi para karyawan. Selain motivasi, reward dan punishment juga bertujuan agar seseorang menjadi giat lagi usahanya untuk memperbaiki atau meningkatkan prestasi yang telah dapat dicapainya .

Di dalam Islam kata reward dan punishment dapat disamakan dengan kata targhîb Adapun arti kata " adalah keinginan yang kuat. Istilah targhîb kerap diartikan dengan kalimat yang melahirkan keinginan kuat (bahkan sampai pada tingkat rindu), membawa seorang tergerak untuk menggerakan amalan. Secara istilah (terminologi), Abdurrahman An-Nahlawi menjelaskan, pengertian targhib sebagai suatu janji yang disertai bujukan dan rayuan untuk menunda kemaslahatan kelezatan dan kenikmatan namun penundaan itu bersifat pasti baik dan murni serta dilakukan melalui amal saleh, atau dari kelezatan yang membahayakan (pekerjaan buruk).

\section{2). Analisis Sistem Reward dan Punishment terhadap Kinerja Karyawan Bank Muamalat Cirebon}

Menurut hasil wawancara penelitian diatas dapat disimpulkan bahwa sistem reward dan punishment ini diberlakukan karena sangat mempengaruhi kinerja karyawan. Karyawan tidak akan bisa bersantai dan berduduk duduk ria karena mereka memiliki tugas atau target yang harus dicapai masing-masing. Minimalnya, para karyawan harus mampu mencapai setengah dari total keseluruhan target KPI. Selain itu pula, dengan adanya reward berupa insentif dan kenaikan jenjang karir juga akan mempengaruhi kinerja karyawan. Para karyawan akan menjadi lebih termotivasi untuk bekerja karena mereka memiliki target atau tujuan yang jelas.

Ditinjau dari perspektif ekonomi Islam, pemberian reward dan punishment juga dianjurkan oleh ajaran agama karena akan berdampak baik bagi kinerja karyawan. Masalah reward dan punishment selain sensitif karena menjadi pendorong seseorang untuk bekerja, juga karena berpengaruh terhadap moral dan disiplin kerja. Oleh karena itu, setiap perusahaan atau organisasi mana pun seharusnya dapat memperhatikan reward dan punishment yang seimbang dengan beban kerja yang dipikul. Dengan demikian, tujuan pembinaan tenaga kerja adalah untuk menciptakan tenaga kerja yang berdaya guna dan mampu menghasilkan produktifitas yang tinggi sesuai dengan harapan perusahaan dapat terwujud. Lebih dari itu, tujuan perusahaan untuk meningkatkan pendapatkan dapat dicapai.

Sebagaimana telah dikemukakan bahwa sistem reward dan punishment yang terapkan dalam internal perusahaan dapat memiliki pengaruh positif langsung terhadap perilaku tenaga kerja yang bersangkutan berkenaan dengan statusnya sebagai salah satu unsur dalam perusahaan. Akan tetapi pada banyak segi, hal tersebut tidak langsung memberi pengaruh terhadap motivasi tenaga kerja untuk berkinerja. Namun motivasi tenaga kerja akan ditentukan oleh perangsangnya. Perangsang yang dimaksud merupakan mesin penggerak motivasi tenaga kerja, sehingga menimbulkan pengaruh perilaku individu tenaga kerja yang bersangkutan. Sistem reward dan punishment merupakan bentuk kompensasi yang menjadi perangsang terhadap karyawan sehingga menumbuhkan motivasi yang tinggi dalam bekerja. 
Reward dan punishment adalah bagian dari manajemen kompensasi. Adapun tujuan dari manajemen kompensasi, yaitu:

1) Sebagai daya darik bagi karyawan guna memperoleh karyawan yang berkualitas;

2) Pemerhatian terhadap karyawan agar tetap setia pada perusahaan guna pememtahankan karyawan. Perputaran tenaga kerja yang sangat tinggi maka diperlukan pertimbangan terhadap pemberian insentif karenanya dibutuhkan pertimbangan yang lebih baik dan menguntungkan antara meningkatkan kompensasi;

3) Imbalan atas prestasi yang setimpal yang diberikan atas kerja keras dan juga prestasi yang telah diberikan karyawan;

4) Mencerminkan adanya keadilan yang mendasari perhitungan pembayaran imbalan sesuai dengan besarnya kontribusi yang diberikan kepada perusahaan;

5) Tidak melebihi dari kemampuan perusahaan kompensasi yang rasional membantu perusahaan memelihara dan mempertahankan pekerja, tanpa menajemen kompensasi yang efektif pekerja dapat dibayar terlalu tinggi atau terlalu rendah;

6) Tidak bertentang dengan peraturan pemerintah. Sistem upah yang wajar mempertimbangka peraturan pemerintah dan memastikan pemenuhan kebutuhan pekerja.

Pengembangan hakikat sistem reward dan punishment yang baik, belum berarti keefektifan terjamin. Akan tetapi, hakikat sistem reward dan punishment setidaknya dapat membantu merumuskan tujuan yang diharapkan dari suatu sistem reward dan punishment. Di samping itu, hakikat sistem reward dan punishment pun dapat memberikan landasan untuk menetapkan suatu keputusan dan tindakan kepada karyawan yang terlibat dalam proses marketing sehingga dapat memberikan integritas dan kredibilitas yang tinggi dalam diri karyawan sehingga akan meningkatkan prestasi karyawan dalam memasarkan produk kepada nasabah.

Sistem reward dan punishment yang dilaksanakan harus memperhatikan banyak aspek sehingga tidak terjadi kesalahan, terutama dalam bersikap terhadap karyawan. Kebutuhan karyawan untuk diperhatikan dan dimotivasi dengan baik perlu ditingkatkan. Memberikan reward dan punishment terhadap karyawan sangat penting agar mereka merasa mendapatkan perhatian dan dorongan untuk terus mewujudkan sesuatu yang terbaik dengan semangat kerja yang tinggi. Sistem reward dan punishment merupakan bagian manajemen konpensasi yang bertujuan untuk membantu perusahaan mencapai keberhasilan strategi sambil memastikan keadilan internal maupun keadilan eksternal yang mana keadilan tersebut menyangkut keberlangsungan perusahaan dan juga jaminan atas pekerja agar mendapatkan kompensasi secara adil. Adapun dalam pemberian kompensasi dalam artian penerapan sistem reward dan punishment kepada karyawa antara lain untuk meningkatkan disiplin kerja, terwujudnya iklim organisasi yang menggairahkan, dan meningkatkann produktivitas kerja.

Adapun pada akhirnya pemberian reward dan punishment ini atas kinerja karyawan dimaksudkan selain untuk menjaga kelangsungan dari perusahaan dan juga menjaga karyawan agar tetap setia pada perusahaan. Tetapi terkadang terjadi konflik yang tidak diinginkan oleh pihak antara tjuan yang ingin dicapai dari pemberian reward dan punishment tersebut. Sehingga diperlukan pencarian titik temu antara pihak pimpinan perusahaan dan juga pekerja dengan memperhatikan keadilan dan juga kelayakan hidup karyawan dengan upah dan sistem reward dan punishment yang diterapkan oleh perusahaan sehingga tujuan perusahan yang telah diprogramkan sebelumnya dapat dicapai dengan maksimal dan sesuai dengan harapan bersama. 


\section{KESIMPULAN}

Berdasarkan hasil penelitian dan pembahasan dapat disimpulkan bahwa jenis reward yang berlaku di Bank Muamalat Cirebon adalah dengan pemberian uang insentif di luar gaji pokok sebesar 0,01 dari target yang didapat yang akan dibayarkan di bulan berikutnya dan juga kesempatan naik jabatan ke jenjang karir selanjutnya. Sistem punishment juga ada dan berlaku di Bank Muamalat Cirebon. Punishment diberikan kepada karyawan yang tidak mampu mencapai setengah atau 50\% target KPI. Namun, pemberian punishment dilakukan secara bertahap mulai dari pemberian surat teguran atau ST, surat peringatan atau SP bahkan hingga akan di PHK.

Sistem reward dan punishment ini diberlakukan karena sangat mempengaruhi kinerja karyawan. Karyawan tidak akan bisa bersantai dan berduduk duduk ria karena mereka memiliki tugas atau target yang harus dicapai masing-masing. Minimalnya, para karyawan harus mampu mencapai setengah dari total keseluruhan target KPI. Selain itu pula, dengan adanya reward berupa insentif dan kenaikan jenjang karir juga akan mempengaruhi kinerja karyawan. Para karyawan akan menjadi lebih termotivasi untuk bekerja karena mereka memiliki target atau tujuan yang jelas. Sistem reward dan punishment juga terdapat dalam Good Corporate Government dimana penerapan GCG pada bank syariah diharapkan semakin meningkatnya kepercayaan publik kepada bank syariah, pertumbuhan industri jasa keuangan Islam dan stabilitas sistem keuangan secara keseluruhan akan senantiasa terpelihara, dan keberhasilan industri jasa keuangan Islam dalam menerapkan GCG akan menempatkan lembaga keuangan Islam sejajar dengan lembaga keuangan internasional lainnya.

\section{BIBLIOGRAFI}

Agustina, Y., Setyowati, T., \& Murtaliningtyas, W. (n.d.). PENGARUH KOMPENSASI DAN DISIPLIN KERJA TERHADAP PRODUKTIVITAS KERJA KARYAWAN UD. MUTIARA RASA JEMBER.

Almasuddini, H. (2019). Strategi Penghimpunan Zakat di Yayasan Nurul Hayat Surabaya. UIN Sunan Ampel Surabaya.

Assagaf, M. F. (n.d.). MORAL DAN ETIKA.

DANANTO, K. (2018). LAPORAN PRAKTIK KERJA LAPANGAN PADA PT BANK NEGARA INDONESIA (PERSERO) TBK KANTOR CABANG UTAMA RAWAMANGUN.

Febrianti, S. (2014). Pengaruh Reward dan Punishment Terhadap Motivasi Kerja Serta Dampaknya Terhadap Kinerja (studi pada karyawan PT. Panin Bank Tbk. Area Mikro Jombang). Brawijaya University.

Hariyati, H. (2011). Time Driven Activity-Based Costing: Konsep Akuntansi Manajemen yang Akurat dalam Menghadapi Lingkungan yang Dinamis dan Bisnis Global. BISMA (Bisnis Dan Manajemen), 3(2), 218-230.

Hidayat, F. (2018). Pengaruh reward dan punishment terhadap kinerja karyawan dengan disiplin kerja sebagai variabel intervening di waroeng spesial sambal Yogyakarta. Universitas Islam Indonesia.

Ishak, K. (2014). Pemikiran Al-Syatibi Tentang Maslahah Mursalah Dan Implementasinya Dalam Pengembangan Ekonomi Syariah. IQTISHADUNA: Jurnal Ilmiah Ekonomi Kita, 3(2), 820-838.

Kurniawan, H., \& Alimudin, A. (2015). Pengaruh Kepuasan Kerja, Motivasi Kerja dan Kedisiplinan Terhadap Kinerja Karyawan PT. Garam (Persero). Ilmu Manajemen Magistra, 1(2). 
Pramesti, R. A., Sambul, S. A. P., \& Rumawas, W. (2019). Pengaruh reward dan punishment terhadap kinerja karyawan KFC Artha Gading. Jurnal Administrasi Bisnis (JAB), 9(1), 57-63.

Rismanto, R. (2019). Analisis kompetensi karyawan, reward dan punishment terhadap kinerja karyawan (survei pada karyawan Koperasi Syariah Nuri Jawa Timur di pulau Madura). UIN Sunan Ampel Surabaya.

Rismawan, R., \& Ar-rasyid, M. N. (2018). Pengaruh Reward dan Punishment terhadap Kinerja Karyawan. Skripsi Universitas Pendidikan Indonesia,(1).

Sumaeni, E. (2018). Pengaruh kedisiplinan dan kompensasi karyawan terhadap kinerja karyawan di Bank Muamalat KC Surabaya-Mas Mansyur. UIN Sunan Ampel Surabaya.

Tangkuman, K., Tewal, B., \& Trang, I. (2015). Penilaian kinerja, reward, dan punishment terhadap kinerja karyawan pada PT. Pertamina (persero) cabang pemasaran suluttenggo. Jurnal EMBA: Jurnal Riset Ekonomi, Manajemen, Bisnis Dan Akuntansi, 3(2).

Yolanda, A., Ranita, S. V., Idris, I., \& Nurismilida, N. (2018). Efektivitas Penilaian Prestasi Kerja Karyawan (Studi Kasus: PTPN IV (Persero)-Kebun Tinjowan Simalungun). Jurnal Bis-A: Jurnal Bisnis Administrasi, 4(2), 69-74.

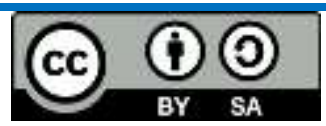

This work is licensed under a Creative Commons Attribution-ShareAlike 4.0 International License 